estudios 


\title{
Derrida y el pensamiento amazónico (La bestia y el soberano / el jaguar y el chamán)
}

\author{
Derrida and Amazonian Thought (The Beast and the Sovereign / the Jaguar and the Shaman) \\ Derrida e o pensamento amazônico ( $A$ besta e o soberano / a onça e o xamã)
}

\section{Juan Duchesne Winter}

UNIVERSITY OF PITTSBURGH, ESTADOS UNIDOS

Profesor de Literatura Latinoamericana en la Universidad de Pittsburgh.

PhD por The State University of New York-Stony Brook. Autor de La guerrilla narrada. Acción, acontecimiento, sujeto (Editorial Callejón, 2010), Comunismo literario y teorías deseantes: inscripciones latinoamericanas (Plural, 2009), Del príncipe moderno al señor barroco: la república de la amistad en Paradiso, de José Lezama Lima (Archivos del Índice, 2008), Equilibrio encimita del infierno: Andrés Caicedo y las utopías del trance (Archivos del Índice, 2007), Fugas incomunistas (San Juan, 2005), Ciudadano insano (Editorial Callejón, 2001), Política de la caricia (Editorial Nómada, 1996) y Narraciones de testimonio en América Latina (Editorial de la Universidad de Puerto Rico,1991). Correo electrónico: duchesne@pitt.edu Artículo de reflexión

Documento accesible en línea desde la siguiente dirección: http://revistas.javeriana.edu.co doi:10.11144/Javeriana.cl21-41.dpab 


\section{Resumen}

Se propone aquí leer la deconstrucción de la soberanía en el seminario de Jacques Derrida, La bestia y el soberano, a la luz del pensamiento amazónico, el cual sugiere que lo que vincula a la soberanía con la animalidad no es necesariamente una común exterioridad con respecto a la ley, sino capacidades compartidas por humanos y no-humanos que no son exteriores ni al lenguaje ni a la política. En los textos chamánicos suramericanos emerge la relación isonómica entre el jaguar y el chamán como expresión de una cosmopolítica en la cual se implican y se contienen mutuamente la soberanía y la libertad, lo humano y lo no-humano, la vida y la no-vida, la ley y su exterioridad.

Palabras clave: Jacques Derrida; amazonía; animalidad; soberanía; chamanismo

\section{Abstract}

This is a proposition to read the deconstruction of sovereignty in Jacques Derrida's seminar The Beast and the Sovereign in the light of Amazonian thought, which suggests that what links sovereignty and animality is not necessarily their common externality vis-à-vis the law but the capacities shared by human and nonhuman beings that are not external to language or the political. South American shamanic texts articulate the isonomic relationship between the jaguar and the shaman as an expression of a cosmopolitics that conveys the mutual implication of sovereignty and freedom, human and nonhuman, life and nonlife, the law and its exteriority.

Keywords: Jacques Derrida; Amazonia; Animality; Sovereignty; Shamanism

\section{Resumo}

Propõe-se aqui para ler a desconstrução da soberania no seminário de Jacques Derrida, A Besta e o Soberano à luz do pensamento Amazônico, o que sugere que a ligação entre a soberania com a animalidade não corresponde necessariamente a uma externalidade comum a respeito à lei, mas as capacidades compartilhadas por seres humanos e não-humanos que não são externas ao linguagem ou à política. Nos textos xamânicos sul-americanos emerge a relação isonômica entre a onça-pintada e o xamã como uma expressão cosmopolítica em que estão mutuamente envolvidos a soberania e liberdade, humanos e nãohumanos, a vida e não-vida, a lei e sua exterioridade.

Palavras-chave: Jacques Derrida; Amazônia; animalidade; soberania; xamanismo

\section{Cómo citar este artículo:}

Winter, Juan Duchesne. "Derrida y el pensamiento amazónico (La bestia y el soberano / el jaguar y el chamán)". Cuadernos de Literatura 21.41 (2017): 168-193. https://doi.org/10.11144/Javeriana.cl21-41.dpab 
En su obra La sociedad contra el Estado, Pierre Clastres dice que ya es hora de que ocurra una revolución copernicana; una conversión heliocéntrica en la cual el estudio de las llamadas culturas primitivas deje de girar en movimiento centrípeto en torno a la civilización occidental (Clastres 25-62), implicando así que los estudios sobre la susodicha civilización podrían más bien girar en torno a las sociedades primitivas. En esta intervención acogemos la sugerencia de Clastres y proponemos realizar una lectura del seminario final de Derrida, La bestia y el soberano (2009-2011), a la luz del pensamiento amazónico, en lugar de someter este pensamiento al rasero de los conceptos del filósofo francés. La relación de Derrida con el pensamiento amazónico es de larga traza y se podría decir que comienza con las extensas páginas que le dedica en una de sus primeras obras a la manera como Claude Lévi-Strauss escenifica la relación de los nambikwara, del Amazonas brasileño, con la escritura (De la gramatología 140-180). Sin dejar de reconocer las posturas anti-etnocéntricas del autor de Tristes trópicos (1955), Derrida demuestra cómo sus presunciones sobre el lenguaje y la escritura movilizan un etnocentrismo estructural que la atribución de una inocencia originaria y primitiva a los pueblos amazónicos no hace sino reforzar. Según Derrida no es fortuito que afecte a las nobles intenciones de Lévi-Strauss un etnocentrismo profundo que [privilegia] el modelo de la escritura fonética, modelo que torna más fácil y legítima la exclusión de la grafía. Pero etnocentrismo que se piensa por el contrario como anti-etnocentrismo, etnocentrismo dentro de la conciencia del progresismo liberador. Al separar radicalmente la lengua de la escritura, al poner esta última abajo y afuera, el creer por lo menos poder hacerlo ..., se piensa efectivamente devolver su estatuto de lengua auténtica, del lenguaje humano y plenamente significante, a todas las lenguas practicadas por los pueblos que empero se continúa llamando "pueblos sin escritura". (De la gramatología 143-144)

Derrida expone cómo el etnocentrismo occidental excluye a los nambikwara y a tantos otros pueblos como ellos al presumir que solamente la notación lineal y fonética puede validarse como escritura, desconociendo que la escritura general es la práctica "de la diferencia clasificatoria", ejercida tanto en el lenguaje humano oral como en todo sistema de trazos en cualquier medio. A su modo, Derrida nos deja ver que son los nambikwara, con su nada inocente y nada primitiva reinterpretación de la escena originaria de la 
escritura armada por el etnógrafo, quienes nos proporcionan una "lección de escritura" ampliada. ${ }^{1}$

Tomemos en cuenta que Pierre Clastres cuestiona el que se considere primitivas a sociedades cabalmente vigentes, activas y contemporáneas, como las sociedades indígenas de América; razón por la cual aquí las llamaremos, no sociedades sin Estado - porque ello reforzaría un sentido de carencia y además no se puede decir que existan completamente fuera del alcance de algún Estado - sino, precisamente, sociedades contra el Estado, en la medida en que, como demostró Clastres, aportan herramientas a la crítica contemporánea del Estado moderno. ${ }^{2}$ Si algo estimula a revisar los fundamentos de la civilización que ha protagonizado el advenimiento del planeta a la era del antropoceno - es decir, a la era definida por la capacidad de los humanos de destruir, mediante una tecnología atada a la producción y a la acumulación infinita, el hábitat mismo que sostiene su vida y la de los seres que los sustentan $-{ }^{3}$ son las sociedades sin estado; parte importante del estímulo revisionista viene de estas; de su pensamiento otro, capaz de cuestionar radicalmente el antropocentrismo destructivo de la sociedad moderno-industrial.

El último seminario de Jacques Derrida enfoca su labor de deconstrucción sobre el misterio de la soberanía para impugnar el estado urbano-agro-industrial, entre otras cosas. ¿Qué hay en la soberanía - pregunta Derrida- que su discurso tantas veces invoca a las bestias, a los animales? ¿ $\mathrm{i}$ Por qué la bestia, preferentemente el lobo, suele aparecer acompañando o personificando al soberano en el discurso occidental? Con esas interrogantes Derrida agarra el hilo suelto que halará y halará durante los dos volúmenes del postrer seminario de su vida para ir desmadejando, desconstruyendo el tejido de la supuesta excepcionalidad del homo sapiens (y su contradistinción tajante de los seres supuestamente no humanos); manto que facilita uno de los escamoteos principales de la soberanía en cuanto poder, maestría y conocimiento único e indivisible de un sujeto que se asume, a su vez, como factor originario de su relación vertical y unilateral con un mundo-objeto. Esta soberanía

1 El etnógrafo llama "Lección de escritura" al episodio en que Derrida basa su discusión. Este episodio es un capítulo del libro de Claude Lévi Strauss, Tristes trópicos. Ver más sobre la deriva Derrida-Sur en el libro de Bruno Mazzoldi, Negro de Yurupary - Púrpura de Prince. Apuntes para una cromometría de la violencia melancólica y también su capítulo "Derrida desde las Indias", en A veces Derrida.

2 Que sean sociedades contra el Estado no necesariamente las inscribe en un programa anarquista de abolición del Estado.

3 Ver el texto de Dipesh Chakravarty "Clima e historia: cuatro tesis", disponible en la Revista Pasajes de la Universidad de Valencia: no. 31, del año 2010, de las páginas 51 a la 68. 
se puede definir, según Derrida, a partir de unas mínimas características indispensables: 1) se basa en un sujeto único (un individuo o colectividad que actúa como tal), que se caracteriza por la ipseidad, es decir, por la propensión a autoposicionarse como siendo siempre no otra cosa que él mismo; 2) es indivisible; 3) se ejerce sobre una totalidad que ella misma instaura, y 4) como corolario de lo anterior, se funda, directa o indirectamente, en un dispositivo de control, coerción y violencia ("la dictadura es siempre la esencia de la soberanía" - dice Derrida-) (The Beast and the Sovereign I, 103). ${ }^{4}$ Pensar la soberanía es más necesario que nunca en la medida en que su ejercicio por parte del Estado postfordista intenta sostenerse cada vez más en nuestro tiempo, antes que en el consenso, la consulta electoral, la influencia, el dominio, la represión o la hegemonía políticamente explícitos, en la captación de los poderes de la vida misma mediante el despliegue de los dispositivos de control al nivel de reglas y normas inmanentes al manejo de los cuerpos. ${ }^{5}$ Como dice Maurizio Lazzarato, "[e]l biopoder coordina y tiene como objetivo un poder que no le pertenece propiamente, que viene de afuera" (32), y se puede decir que viene "de abajo', con lo que se incluyen multiplicidades; procesos que involucran incontables formas de vida, especies múltiples de animales, microorganismos y plantas participantes en el ambiente forjado por la sociedad humana urbano-agro-industrial. Esto no significa que la soberanía y la ley se retiren (Lazzarato 31), sino que el poder se intenta reconfigurar por vía del manejo de las multiplicidades multiespecies que desbordan las poblaciones humanas, si bien se interpenetran con estas vías todo tipo de relaciones en la alimentación, la agro-industria, el manejo y la disposición de los cuerpos y la salud, así como de la habilitación de los espacios y territorios. Ahí reside la gran pertinencia de iniciar todo pensamiento sobre la soberanía con el pensamiento del animal y sus mutaciones: como la de la bestia. Sin adoptar los términos biopoder o biopolítica como parte de su vocabulario, Derrida inscribe su discusión sobre la soberanía precisamente en esa transformación contemporánea del poder del Estado. Una hipótesis importante de Derrida sobre la relación histórica y social del animal con el humano es que nos enfrentamos en la actualidad a una mutación y transformación sin precedentes en "lo que seguimos llamando imperturbablemente, como si nada hubiera ocurrido, el animal y/o los animales", a raíz de una "experiencia en la que llegan a temblar los límites del paso de las fronteras entre bios y zoé, zoológico y antropológico, igual que entre vida y muerte,

\footnotetext{
La traducción al español de todas la citas tomadas de ediciones en otras lenguas es mía.

5 Ver el texto de Cary Wolfe, Before the Law. Humans and Other Animals in a Biopolitical Frame, páginas 31 y 32 .
} 
vida y técnica, vida e historia, etc." (El animal que luego estoy si(gui)endo 40-41). ${ }^{6}$ No es que este seminario nos revele exactamente cuál es el misterio de la relación existente entre la bestia y el soberano en el imaginario occidental, pues no pretende tal cosa, sino que lo aprovecha como acicate de un pensamiento emancipador.

Proponemos aquí aproximarnos a este pensamiento de Derrida con ayuda de un pensamiento otro, recurriendo a preguntas similares pero invertidas en cierta manera; es decir, vertidas desde una perspectiva muy diferente e inscritas en un ámbito inconmensurable, en términos de sus ontologías y dimensiones imaginarias, pero por eso mismo especialmente capaces de afectar y afectarse. En el discurso amazónico, es decir, en el discurso de la sociedad contra el Estado por excelencia, la figura del chamán viene también misteriosamente acompañada de animales y a veces es personificada por ellos: preferentemente el jaguar, en aparente paralelismo con el soberano occidental y el lobo. Así, al lobo y el rey corresponderían el jaguar y el chamán. Sin embargo, resulta que el poder y el conocimiento del chamán no responden al concepto occidental de soberanía, en la medida en que no configuran un sujeto único de poder y mucho menos indivisible, ni se fundan en una relación unilateral con un mundo-objeto, además de no suponer el control total de ninguna parcialidad. El chamán no es soberano en ese sentido, y como se sabe es solo una de las figuras de influencia en una sociedad que cuenta con varias, entre ellas el llamado jefe o capitán de maloca que, a su vez, tampoco es soberano en el sentido antes descrito (aparte de que ambas funciones pueden ser ejercidas por la misma persona). Aunque se relaciona con conocimientos especializados y esotéricos usualmente apropiados por élites, como dice Irving Goldman, el chamanismo se presenta como un campo de conocimiento esotérico especializado que está abierto a los marginales y subalternos (Cubeo Hehénewa Religious Thought 97). A esto hay que añadir que los animales de pensamiento a los que usualmente se asocia la figura del chamán, como el jaguar, la boa y otras especies y seres no-humanos en general, son considerados seres capaces de asumirse como personas; sujetos que cuentan con una perspectiva comparable a la humana, y no como meras "bestias" (en cuanto

6 Dicha transformación se basa en las alteraciones producidas bajo el biopoder soberano: "por la cría y el adiestramiento a una escala demográfica sin parangón con el pasado, por la experimentación genética, por la industrialización de lo que se puede llamar la producción alimenticia de la carne animal, por la inseminación artificial masiva, por las manipulaciones cada vez más audaces del genoma, por la reducción del animal no solamente a la producción y a la reproducción sobreactivada (hormonas, cruces genéticos, clonación, etc.) de carne alimenticia sino a toda suerte de otras finalidades al servicio de cierto ser y supuesto bienestar humano del hombre"(El animal que luego estoy si(gui)endo 40-41). 
objeto completamente ajeno a la subjetividad humana normativa), cual es el caso del animal en el discurso occidental dominante.

Surgen preguntas: ¿Qué hay en el poder y conocimiento del chamán que siempre aparece relacionado con animales (con frecuencia el jaguar, pero también la boa, el águila y otros)? ¿Cómo es posible que una figura como el chamán, que ni siquiera puede asegurarse que es un individuo, sino que se transforma y se compone de muchos entes con intenciones disímiles y contradictorias, posea poder y conocimiento soberanos? ¿Qué pensar de una soberanía como la del chamán (si ella puede llamarse soberanía), que para empezar le viene transmitida de múltiples seres a quienes se afilia (o que lo afilian), que siempre se divide, se disemina y discurre en sus negociaciones con innumerables animales, vegetales, minerales, meteoros climáticos, astros, imágenes, ideas, instrumentos, indumentarias, canciones, bailes, gestos, palabras, todos y cada uno con estatuto de sujeto y de persona similar al humano? Habría que examinar, en fin, hasta dónde estas preguntas alcanzan alguna tangencia con las preguntas claves de La bestia y el soberano.

Derrida inicia su primera sesión del seminario el 12 de diciembre de 2001 advirtiendo que discurrirá durante el mismo con el sigilo de un lobo (The Beast and the Sovereign I, 21, 55). Dice que el tema del que se habla de por sí convoca a los animales. Aquí se van a arrimar los lobos — avisa-. Intercala en sus disquisiciones referencias a lobos que pululan por ahí cerca mientras habla. Mucho más adelante en otras sesiones no deja de insinuar que el seminario es un teatro de animales. Incluso Derrida alude a la máscara negra de terciopelo llamada "lobo", usada antaño por las damas francesas para mirar sin ser vistas en ocasiones sociales, con lo cual remite al "efecto de visera" de la soberanía y a su aspecto espectral (26), metaforizado en Hamlet con la visera de combate tras la cual se emite la voz del soberano fantasma que es padre del príncipe. Mientras uno lee tales cosas no puede sino recordar los bailes de muñeco en el Amazonas, en donde se invita a los espíritus (espectros) de los animales de la selva a bailar en la maloca, hechos cuerpos-máscaras. Literalmente hechos, pues son fabricados y actuados, estos animales del baile no son símbolos ni manifestaciones de un espíritu exterior a la máscara, sino que son la máscara y la actuación de la máscara en sí. ${ }^{7}$ El filósofo de la deconstrucción, a su manera, trata de invitar a los animales a su seminario. Pero no es que él se proponga cantar y bailar con ellos como el maloquero, sino que quiere dejar claro que su propio ejercicio del discurso académico, en la medida en que no puede ser otra cosa que

7 Sobre el baile de muñeco amazónico ver el libro compilado por Kaj Århem, Luis Cayón, Gladys Angulo y Maximiliano García, Etnografía Makuna. Tradiciones y saberes de la Gente de Agua: páginas 154 a 165. 
un monólogo enmarcado en un saber tan institucionalizado como la filosofía - tras el cual hay un Estado que mira sin ser visto, no quepa duda - es en sí mismo una expresión de soberanía, y de la dura. Por eso él afirma, en la undécima sesión, el presentimiento, la sospecha de que el orden del conocimiento nunca es extraño al del poder... especialmente el conocimiento en la forma de la objetividad del ob-jeto; el conocimiento que tiene a su disposición, yacente ante él como un objeto, aquello que sabe y quiere saber (The Beast and the Sovereign I, 280-281). Mencionar la soberanía, y encima ejercerla de una manera tan aparentemente suave y cordial como la del profesor en el seminario, es ya invitar a los animales: aquello es lo que enfatiza Derrida. ¿Por qué? ¿Cuál es la relación? Nuestro profesor favorito tiene la delicadeza de no pretender resolver del todo ese misterio, y en ello cede no poco de su inevitable participación en el discurso soberano. Pero sí indica que la relación existente entre el animal y el soberano pasa por la exterioridad a la ley. No se trata tanto de cualidades propias compartidas cuanto de una exterioridad compartida (16-17). ${ }^{8}$ En la polis occidental, es decir, en la sociedad del Estado, el soberano, como sabemos, instaura la ley gracias, precisamente a que se ubica por fuera de la ley. Solo el acto de fuerza no restringido por la ley puede instalar la ley. Es el mismo principio lo que determina que se requiera un punto inmóvil externo para que se mueva la palanca; que se necesite una mácula no vidente en la retina para que el ojo vea; que no se pueda postular lógicamente la existencia del mundo sin admitir a su vez otro mundo que lo contenga y así sucesivamente. En fin, ninguna cosa se puede afectar ni contener a sí misma: necesita de otra. Nada tiene sentido si no tiene al menos dos sentidos. Toda cosa es la diferencia entre aquello que la contiene y lo que ella contiene en sí (Garcia 19-22). ${ }^{9}$ Para parafrasear una formulación de Tristan Garcia, ${ }^{10}$ la ley no es otra cosa que la diferencia que hay entre lo que está dentro de ella y lo que está fuera de ella.

Volviendo a la bestia y el soberano de Derrida, ambos personajes pasan por la exterioridad a la ley que permite la existencia de la ley. Por eso comparecen juntos cada vez que se habla de la ley fundada por el poder soberano. A Derrida no le interesa usar esa complicidad en la frecuentación de la exterioridad a la ley para señalar: ¡sí, vean, así como la bestia, es el soberano, cuyo poder se funda en el salvajismo, la brutalidad y la estupidez de la bestia pese a todas las máscaras humanistas! Ese es un tópico gastado que no merece dos volúmenes. No, en verdad nuestro autor nos da a entender que no es necesariamente la animalidad lo que hermana al soberano

\footnotetext{
8 Ver pássim.

9 Ver pássim.

10 Este autor usa su nombre sin tildes, de acuerdo a la ortografía francesa.
} 
con la bestia (qua animal), y ni siquiera queda muy claro por qué la exterioridad a la ley deba convocarlos por igual. Derrida parte del hecho de que se los convoca a ambos a comparecer juntos. Pero lo que nos pregunta es si acaso debemos dar por sentadas las premisas de tal convocatoria, que de todos modos no es sino una construcción histórica del sentido de la soberanía y no una disposición esencial del ser. Y tengamos en cuenta que cuando Derrida habla del sentido, no se limita a la semántica del lenguaje, sino que incluye el sentido del cuerpo, su orientación en un campo determinado, su movimiento, el gesto, el acto, la interacción. ${ }^{11}$ ¿Cuáles son las premisas de la soberanía que le otorgan sentido al acto de colocar lado a lado a la bestia y al soberano en esa exterioridad que les es paradójicamente constitutiva? Las cosas no empatan por completo: hay un hilo suelto, uno al menos, del que va a halar Derrida. Se presupone que el animal, por serlo, por pertenecer a la naturaleza, queda fuera del lenguaje, de la cultura, de la política, fuera de todo eso que se presume pertenece exclusivamente al humano, quien si bien no se niega que proviene de la naturaleza, se elevaría por encima de ella gracias al corte con todo el resto del universo que le otorgarían el lenguaje y la cultura. Ahora bien, aquello crea fricciones, porque entonces el soberano, al alzarse por encima de la ley para instaurarla, incursiona en la exterioridad natural, salvaje, que correspondería al animal, y de paso, nos recuerda Derrida, a las gentes 'salvajes' que aquí llamamos sociedades contra el Estado, cuales los amazónicos a quienes los curas conquistadores del Brasil acusaban de vivir "sin dios ni rey ni ley" — es decir, sin soberanía (cual esta se entiende desde la sociedad de Estado) - . Esta es la complicación: es decir, que esta soberanía tiene asidero en la exterioridad natural, salvaje e incivilizada que supuestamente es el predio por excelencia de los animales y las gentes equiparables a ellos por vivir "sin dios ni rey ni ley". ¿Cómo es posible que pulule entre las bestias y los salvajes ese soberano que se arroga el poder y el conocimiento indivisible de la totalidad; cuyo puesto es equiparable al de Dios y cuyas prerrogativas son cuasi divinas y vienen avaladas, cuando no por Dios, por una ontoteología metafísica perfectamente equivalente? Hablamos, en las sociedades contemporáneas, no ya del personaje del rey, sino del soberano en cuanto Estado. Ese soberano que encarna la ley pero que también para supuestamente preservarla encarna la violación de la ley: el soberano que maneja la disposición de los cuerpos contra el contagio; que reglamenta los parámetros de la intoxicación, la desviación y la normalidad; que maneja la transgresión; que maneja la parapolítica y la narcopolítica; el soberano que se arroga los parámetros del derecho internacional pero que maneja drones a

11 El propio texto lo da a entender en numerosas instancias. Ver también una formulación explícita sobre el "sentido" en Posiciones de Jacques Derrida, páginas 52 y 53. 
miles de kilómetros de distancia para asesinar personas que se enteran de que han sido acusadas y condenadas a muerte por terrorismo justo cuando les cae el cohete encima, con el pequeño detalle de que luego se determina que la mayoría son objetivos equivocados, es decir, no vinculados al susodicho terrorismo (Scahill).

Derrida se involucra con paciencia de santo en prolongadísimas disquisiciones sobre las quimeras, los monstruos, los leviatanes que produce en la literatura filosófica esa incómoda e inestable contigüidad en la exterioridad natural que las prerrogativas divinas y ontoteológicas del soberano humano comparten con las incurias atribuidas a la bestia y el salvaje. Su seminario ocupa dos volúmenes interesantísimos al respecto. Reciben palos críticos, por su renuencia a siquiera pensar el potencial del animal para ser sujeto del lenguaje, de la política y la soberanía, autores como Heidegger, Lacan, Agamben y hasta Deleuze, el famoso defensor del "devenir animal". El segundo seminario se dedica mayormente a leer a Heidegger en contrapunto con la novela Robinson Crusoe (1719) de Daniel Defoe, demostrándose a la saciedad el fracaso rotundo de los argumentos de Heidegger para excluir al animal de toda relación de continuidad con el humano, para negarle al animal el acceso al lenguaje y la capacidad de asumir la muerte y el mundo. ${ }^{12}$ En la última sesión de su postrer seminario, Derrida resume: "En el fondo, toda esta gente, desde Defoe a Lacan, vía Heidegger, pertenece al mismo mundo en que se excluye al animal de lo humano mediante un efecto múltiple de poder", el mismo mundo en donde, según ha dicho, "la relación del sujeto soberano de conocimiento y poder hacia los salvajes, las mujeres y la bestias es una relación de condescendencia, de descenso vertical de un amo superior hacia sus esclavos, un soberano hacia sus sujetos sumisos, sumisos o subyugables, dominados o por ser dominados por la violencia si necesario - sometidos" (The Beast and the Sovereign II, 278).

A todo esto, la interrogación derrideana en este renglón del lenguaje y el animal va más allá de disputar si los animales tienen la facultad del lenguaje o no. Sin dejar de examinar esa pregunta, el autor también invita a formular otras: ${ }_{\mathrm{C}}$ Es por fuerza el lenguaje un parámetro para dirimir la relación humano-animal? ¿Qué tal que el animal esté por encima de la necesidad del lenguaje (glotal, humanoide) porque este le parezca sencillamente irrelevante, inútil? El cuestionamiento debería ser obvio. En tal caso, el lenguaje resulta ser un requerimiento capricho-

12 Derrida no deja de reconocer, sobre todo en el segundo volumen del seminario y en su otro libro póstumo (El animal que luego estoy si(gui)endo), las inflexiones sutiles del pensamiento de Heidegger, que invitan a pensar el Dasein como condición básicamente animal y no-humana en general. Ver también el libro de Cary Wolfe, páginas 79 y 80. 
so, antropocéntrico, a partir del cual se atribuye una carencia improcedente. El antropólogo Hugh Raffles tiene palabras más fuertes sobre la improcedencia y la incapacidad de "sólo poder imaginar la socialidad y la comunicación mediante algo parecido al lenguaje, para entonces atribuirnos la supremacía [humana]", falla del propio lenguaje científico sobre la cual exclama: "qué estupidez ... que tristeza tan triste, triste, triste..." (Insectopedia 200). Para Derrida no es ocioso meditar sobre las capacidades que otras especies comparten con el homo sapiens, como se ve en este seminario, pero su consideración fundamental no es el lenguaje sino la igual capacidad de sufrir (El animal que luego estoy si(gui)endo 27).

No podemos entrar en los detalles de la deconstrucción de diversas expresiones de la literatura y la filosofía relacionadas con estos temas, pero corresponde aquí resaltar que desde un principio Derrida establece como regla desconfiar de los límites comúnmente acreditados a la oposición entre lo que llaman naturaleza y cultura; ${ }^{13}$ entre lo que es propio del animal y lo que es propio del hombre. En este sentido queda claro para Derrida que la cuestión, como señalamos antes, no es reconocer que pese a todos los reclamos humanistas e hipostasis divinas el hombre político sigue siendo más animal que otra cosa - ese es un enfoque limitado - sino que el propio animal es ya de entrada político, toda vez que se abre la puerta a considerar que el lenguaje, la cultura, la sociedad, el poder, y la propia soberanía no son exclusivas del homo sapiens. Derrida abre una puerta portentosa en el seno de la más clásica tradición de la filosofía en un tema que, sin ser nuevo, ha sido marginado. Existe hoy día una crítica al antropocentrismo, recogida por cierta vertiente de los llamados estudios post-humanos, algunas de cuyas expresiones podemos calificar de reduccionistas, ${ }^{14}$ consistentes en negar la excepcionalidad de lo humano, pero reduciéndolo, junto a todos los seres vivos, a la mátesis programada y programable, y sobre todo digitalizable, de lo que una tecnociencia positivista y estrecha define como materia. Se contrapone la vida a la muerte en tanto y en cuanto se insiste en remitir la vida a la supuesta alteridad absoluta de la materia-muerta. Derrida no va por ahí. Él deconstruye el antropocentrismo con generosidad: admite la posibilidad de que haya animales que posean lenguaje, política e incluso soberanía y reitera la improcedencia de afirmar que la soberanía sea cosa exclusiva del humano. Es cuestión de pensar a la altura de las investigaciones en zoología. Derrida estima que quienes todavía refutan el acceso del animal al lenguaje lo hacen con base en un manejo incom-

13 Cualquier consideración de este asunto hoy día debe tener en cuenta la obra seminal de Philippe Descola, Beyond Nature and Culture.

14 Confróntese con el texto de Ray Brassier, Nihil Unbound. Enlightment and Extinction. 
pleto y burdo de los conocimientos y las investigaciones que se han elaborado al respecto. Antes de sentarse a emitir sentencias ontoteológicas sobre el tema, hay que darse a la tarea de examinar la bibliografía científica tal como lo ha hecho este filósofo; bibliografía que contiene estudios reveladores sobre el lenguaje de delfines, primates y aves, aparte de los contundentes hallazgos verificados en el mundo vegetal. ${ }^{15}$ En suma, la deconstrucción del antropocentrismo realizada por Derrida lo que hace es incluir a los supuestos no-humanos en ámbitos que la ontoteología reserva para los humanos. No los ha invitado a cantar y bailar en el seminario, tal cual hace el maloquero en el baile de muñeco, pero sí piensa desde esa posibilidad inminente. Nos hemos referido a no-humanos en general, pues aunque el llamado reino animal protagoniza estos debates, el seminario siempre deja abierta la posibilidad de incluir a las plantas, así como muchas otras clases de seres, bióticos y abióticos. La inclusión de los seres abióticos o inorgánicos apunta más allá del vitalismo. Este es el sentido de la sutil recurrencia durante gran parte del seminario de la pregunta “¿Qué o quién?" — referida, al humano, al animal y al no-humano en general-. El "qué" se referiría presuntamente a un objeto, una simple cosa, mientras el "quién" se referiría a la persona, al sujeto. La pregunta asume una pauta musical, pasa por varias tomas y retomas, a manera de ritornello, para finalmente desembocar en una fascinante discusión de la charlapoema de Paul Celan sobre las marionetas y el arte, momento en que se desfonda conceptual e imaginariamente la oposición entre el qué y el quién, de tal manera que se mina cualquier separación dicotómica entre la vida y la muerte; entre los que pertenecen a una indefinible e imposible macro-sustancia llamada "vida" y los que quedan fuera de ella (The Beast and the Sovereign I, 140, 160-162, 183, 199, 250, 264, 277). ${ }^{16}$ Es en el segundo año del seminario (y el segundo volumen) donde se deconstruye meticulosamente cualquier oposición tajante, ontoteológica, entre seres vivientes y no vivientes, con base en una lectura rigurosamente crítica de Heidegger que aprovecha tanto sus bloqueos como sus aperturas. Por ejemplo, entre otras cosas, al voltear hábilmente las pontificaciones de Heidegger

15 Existe la hipótesis experimental, un tanto coincidente con la zoología amerindia, de que al menos algunas especies poseen una capacidad mental similar a la humana que les permite acceder al lenguaje glotal pero cuyas anatomías no responden a esa capacidad, quizás por la razón muy práctica de que para ellas sea superflua. Ver el trabajo de W.A. Hillix y Duane Rumbaugh, Animal Bodies, Human Minds. Ape, Dolphin, and Parrot Language Skills (New York: Kluwer Academic/Plenum Publishers, 2004). Ver "Sobre el lenguaje en las plantas"; selección bibliográfica en el texto de Stefano Mancuso y Alesandra Viola, Brilliant Green. The Surprising History and Science of Plant Intelligence.

16 Ver pássim. 
sobre el ser humano como el único mortal del universo, Derrida aprovecha la oportunidad de ese argumento para entender, implícitamente, que más que seres vivientes y no vivientes, quizás haya seres que mueren y seres que no mueren, pero nada impide, ontológicamente, que sean también vivientes aquellos que de una forma u otra no mueren, tanto como aquellos que mueren pero cuyos trazos no parecen morir (II, 114-115). Se trata de un seminario a puerta abierta, literalmente, al cual han entrado animales, máscaras, fantasmas, muertos y muertos vivientes, revenants (I, 187, 219; II, 130-132). ${ }^{17}$

A mi juicio, para salir de este seminario de la Bestia y el soberano con algún fruto no se pueden dejar de percibir tres énfasis puntuales. El primero es que la deconstrucción de la soberanía nunca acaba. No se pretende haber resuelto el misterio de la soberanía mediante la crítica de la soberanía. El aliento emancipador de este ejercicio deconstructivo pasa por el despliegue de más amplias zonas de pensamiento. La deconstrucción no busca resolver misterios, sino profundizarlos, expandirlos, democratizarlos. No se pretende convertir la soberanía en el muñeco de paja a quemar para salvarnos del mal. Como advierte Derrida, no se puede prescindir de la soberanía tout court, así como así, pues ella es el punto de basculación entre la libertad y la sujeción. No podemos pensar en la libertad, entendida como autonomía, autodeterminación y emancipación, sin partir de un pensamiento de soberanía, con su ilimitado "yo puedo" - dice él (I, 301) - . Es algo que no se pretende negar aquí. La libertad remite a la soberanía y viceversa. Se trata de un double bind, enfatiza Derrida (I, 301), que debe someterse a una deconstrucción interminable. Tan imprescindible es la soberanía que se requiere pensarla como modalidad potencial atribuible a seres humanos y no-humanos por igual: animales soberanos, plantas soberanas, bosques soberanos, muñecos (marionetas), revenants soberanos: que se abran cien flores soberanas. Lo que sí concluye Derrida es que "la opción y la decisión no es entre una soberanía indivisible y una no-soberanía [también] indivisible, sino entre plurales divisiones, distribuciones, economías ... economías de una soberanía divisible" (I, 302, cursivas del autor). Hay que destacar estas palabras soltadas como de paso, pues son cruciales.

El segundo énfasis consiste en no tomar argumentos tan generosos sobre la inclusión de los animales como una apología exotizante e idealizante del 'buen animal' equivalente al 'buen salvaje'. Derrida advierte contra el antropocentrismo contenido en la celada del "buen animal" (I, 82). Por cierto, Gilles Deleuze pro-

17 Ver pássim. Es una pena no poder discutir aquí las implicaciones pansiquistas y animistas de las discusiones sobre la marioneta, el fantasma y los "living dead" (muertos vivientes) en este seminario. 
nunció palabras interesantes que distancian la cultura occidental de la mascota (Abecedario de Gilles Deleuze (1988) - De la "A" a la " $Z$ ") $)^{18}$ con respecto a lo que él y Félix Guattari llamaron el "devenir-animal", concepto que admite el intercambio de afectos y capacidades del humano y animal que no suponen la confusión ni conversión de uno en el otro sino la creación de un tercer evento o proceso, que es el devenir mismo (Mil mesetas. Capitalismo y esquizofrenia II 240, 244, 276-277). ${ }^{19}$ Derrida radicaliza aun más el cuestionamiento de la frontera humano-animal. Su fascinante libro El animal que luego estoy si(gui)endo medita la animalidad desde la perspectiva del hombre urbano europeo. En mis conversaciones con pensadores de la selva he podido constatar que desde la perspectiva del pensamiento amazónico la estructura sentimental de la relación con la mascota casera es una provincia europea. La relación con el animal, aun si se trata de una mascota, de quien caza o pesca para comer en un ambiente no industrial, es muy distinta de la de quien cría un animalito en su apartamento mientras come carne y utiliza productos relacionados con las industrias de procesamiento de animales: factorías de cría, mega-mataderos, laboratorios, etc. Sin embargo, merece una atención específica este libro de Derrida, también póstumo y muy cercano a La bestia y el soberano, en cuanto realiza una investigación de gran alcance que voltea la fenomenología local de la cual parte, y deconstruye radicalmente la noción misma del "animal", hasta el punto de cuestionar la línea de frontera tan dicotómica que el legado ontoteológico occidental ha impuesto entre las figuras del "hombre" y el "animal", con el propósito de complicar, espesar, desalinear, plegar, dividir esa línea sin pretender en absoluto borrarla (El animal que luego estoy si(gui)endo 46). Y en este punto cabe mencionar el tercer énfasis: por conveniencia lingüística todavía usamos en contraposición las palabras humano/animal, suponiendo que la distinción es obvia e indiscutible, pero valdría la pena explorar si en ciertos casos es mejor referirse más bien al homo sapiens y a otras especies, y más si tomamos en cuenta la concepción amazónica de que en el modo primario de existencia todos o casi todos los seres existentes son virtualmente humanos. Sin embargo, aquí hay que actuar con gran cautela, pues según tal concepción esto no borraría para nada la diferencia humano/animal, dado que en el modo secundario de existencia los sujetos de cada una de las distintas especies se consideran ellos mismos como humanos y miran como 'meros' animales a todas las

18 Video en: https://www.youtube.com/watch?v=DRU278pPDLQ

19 Ver pássim. 
demás especies, incluyendo al homo sapiens. ${ }^{20}$ Tengamos en mente esta inflexión de lo derrideano con lo amazónico mientras pasamos al dúo del jaguar y el chamán.

Confieso que he leído La bestia y el soberano a la luz de un pensamiento chamánico, amazónico, que no deja de ejercer su soberanía, en cuanto pronuncia palabras de conocimiento. Remito aquí a dos textos: Misterios de los chamanes-jaguar del Amazonas noroccidental (2013), de Robin Wright, y La caída del cielo. Palabras de un chamán yanomami (2010), de Davi Kopenawa y Bruce Albert. Ambos articulan y sintetizan enseñanzas de chamanes del noroeste amazónico en Brasil. Tanto Robin Wright como Bruce Albert compartieron durante décadas con los chamanes que aportan el contenido de sus libros. El primero cita, traduce, parafrasea y comenta las palabras de Mandu da Silva, José García y otros chamanes-jaguar de la etnia baniwa. El segundo consiste en un extenso testimonio-manifiesto del chamán yanomami Davi Kopenawa, con transcripción, traducción, edición y notas de Bruce Albert. ${ }^{21}$ En su propia factura estos textos distribuyen la soberanía del saber-poder, pues su enunciación nunca es una, siempre es divisible, es legión. Los chamanes que enuncian estos discursos no emiten una sola voz, sino una multitud de redes de enunciación: textos, en el sentido derrideano. Para empezar no han redactado los textos que les citan, lo que ya incluye las voces de los académicos editores que transcriben sus comentarios y alocuciones orales. De hecho, por su propia manera de llegarnos, el pensamiento amazónico no puede ser uno e indivisible, ni siquiera en el sentido mínimo de contar con una autoría individual, ya

20 Philippe Descola, pese a aceptar que el pensamiento amazónico postula un concepto de humanidad reflexiva generalizada (cada especie se ve a sí misma como humana), ha expresado escepticismo ante las aserciones de Viveiros de Castro en el sentido de que esta humanidad reflexiva a su vez entraña necesariamente un corolario inverso recíproco: que cada especie, desde su posicionamiento humano, ve a las otras como animales, incluyendo al homo sapiens. Ver el texto de Descola, páginas 140-143, y el de Eduardo Viveiros de Castro, Metafísicas caníbales. Líneas de antropología postestructural, páginas 50-51, y pássim. Personalmente he consultado pensadores en el río Mirití-Paraná del Amazonas colombiano que sostienen que solo se sabe que cada especie se ve a sí misma como humana, pero también he consultado a otros que sostienen que además se sabe que cada especie ve a todas las demás, incluyendo al homo sapiens, como animales. En lo que sí coinciden es en que en un plano o modo primario de la experiencia, todos son capaces (en potencia) de verse recíprocamente como humanos (lo anterior se deriva de conversaciones entabladas con Orlando Matapí [en junio de 2015] y Ciro Matapí [en noviembre de 2015]).

21 Ver textos en las lenguas originales, de Robin Wright, Mysteries of the Faguar Shamans of the Northwest Amazon, y de Davi Kopenawa y Bruce Albert, La Chute du ciel. Paroles d'un chaman yanomai. 
que debe pasar por la lectura e interpretación del etnógrafo que lo registra y organiza para nuestra lectura, quien se inscribe en el proceso de transmisión y elaboración escrita como autor o co-autor. No estamos, por tanto, ante la expresión indivisible y completamente autógena de algo que se pueda llamar 'pensamiento del indio'. De la misma manera que cuando leemos a Derrida no obtenemos una imagen de cómo piensa el francés, el europeo o el occidental promedio, tampoco al estudiar lo que cuentan los chamanes obtenemos una imagen de cómo piensa el indio en general, sino versiones y variantes sin fin de una gran tradición oral inventada y desarrollada a lo largo de siglos por custodios muy especiales. Esto no impide que las coincidencias entre las versiones, aun entre las que provienen de linajes étnicos relativamente separados por lengua y geografía, sean impresionantes, ni que conformen un cuerpo muy denso y extenso de nociones, imágenes y conceptos comunes. Tal es la composición y factura de lo que aquí llamamos pensamiento amazónico.

Solo al nivel de la más superficial semblanza gráfica y nominal se puede decir que la bestia es al soberano lo que el jaguar al chamán. Une a ambas parejas una homología puramente formal y esquemática que debemos, sin embargo, agradecer, pues provee el fondo para interesantes contrastes. Como hemos señalado al principio, la perspectiva amazónica invierte la orientación de la pareja de la bestia y el soberano. En el análisis que realiza Derrida de este dispositivo vimos que lo que uniría a ambas figuras es su presunta frecuentación (cuestionada por Derrida) de una exterioridad con respecto al predio político de lo humano, y que además causa fricción en el campo ontoteológico el hecho de que esta exterioridad implique la animalidad del soberano. Sin embargo, el punto de vista amazónico sería que lo que sí une a ambos es la humanidad, no una exterioridad compartida con respecto a esta, pues "[l] condición común a los hombres y los animales no es la animalidad sino la humanidad" (Viveiros de Castro 50). Como dice Viveiros, este giro de perspectiva afecta la noción de lo humano, pues la diferencia que hay entre lo humano y lo animal no separa unas clases de entes de otras sino que se traslada al interior de cada ente, a partir de lo cual, "donde todas las cosas son humanas, lo que es humano es otra cosa" $(44,51) \cdot{ }^{22}$ Estas afirmaciones remiten a una estructura ontológica sutil y paradójica que importa examinar brevemente. Comencemos por la bestia (que en la mayoría de los casos es un lobo) y por el jaguar (cuyo lugar pueden ocupar otros animales). Ya vimos que, dentro del dispositivo simbólicopor el tema de la animalidad en textos como el ya citado, El animal que luego estoy si(gui)endo, partes del cual aparecen en el seminario que nos ocupa. 
imaginario de la soberanía occidental examinado por Derrida, el lobo es bestia salvaje excluida del espacio humano por la sustracción de facultades: se le sustrae la lengua, el pensamiento, la capacidad de asumir la muerte y el mundo, etc. Así, el lobo es pura variable sustractiva: $A=-x$ (lo que no quiere decir que sea nada). Sin embargo, en el pensamiento amazónico el jaguar es, para empezar, dos, y en consecuencia, suma variable de facultades: $A=2+x$. Esto es así porque en dicho pensamiento todo comienza con el dos. Para usar las palabras de Davi Kopenawa, tal cual traducidas por Bruce Albert del yanomami al francés, cada ser es su imagen y su fantasma. Notemos que la división por dos no separa necesariamente lo espiritual de lo corporal en el sentido de separar un orden exclusivamente inmaterial de otro orden exclusivamente material. Pero tampoco es que materia, cuerpo, alma y espíritu sean todo lo mismo. Como apunta Eduardo Viveiros de Castro en una de sus ingeniosas interpretaciones, el cuerpo es el alma del alma y el alma es el cuerpo del cuerpo. ${ }^{23}$ Con ello Viveiros no pretende anotarse una cantinflada, sino dar a entender que el pensamiento amazónico no disuelve estas oposiciones (hay alma y hay cuerpo, sin duda), sino que las distribuye según una lógica relacional y perspectivista afín al principio de la mutua inclusión. ${ }^{24}$ En las explicaciones de Kopenawa, quien, según Albert, prefirió que se tradujera como "imagen" lo que los blancos llaman "espíritu", queda claro que la imagen es en sí misma un tipo de corporalidad y de materialidad, al igual que lo es el "fantasma". Hay que aclarar, además, que lo que Kopenawa llama imagen no es una representación mimética, una copia del fantasma, sino que es su forma de ser otro. Por eso cuando uno ve la imagen del jaguar, ${ }^{25}$ lo que uno ve es una persona humana, pues esta imagen no es una imitación o representación del jaguar sino su ser-otro, en vista de que el aspecto zoomórfico del jaguar es el fantasma de esta imagen; su máscara. La división categorial se opera más bien entre dos modos de existencia fundamentales en este pensamiento: un modo primario, ámbito de las imágenes, y un modo secundario, ámbito de los fantasmas de estas. En el vocabulario usado por Robin Wright para traducir el discurso baniwa de Mandu da Silva, el modo existencial primario es el "mundo otro" y el modo existencial secundario es "el mundo este". Lo pertinente es que no son los ejes corporeidad/incorporeidad o materialidad/inmaterialidad los que distinguen fundamentalmente estos modos, sino el conjunto de su moda-

23 Referencia no hallada de Eduardo Viveiros de Castro.

24 Sobre la importancia del principio lógico de la mutua inclusión para el pensamiento del devenir-animal ver el libro de Brian Massumi, What Animals Teach Us about Politics, páginas 32 a 34 .

25 Kopenawa no se refiere aquí al jaguar, pero obviamente su concepto es aplicable al ejemplo. 
lidad existencial como tal. El modo primario se caracteriza por ser el dominio de la plasticidad y la metamorfosis; es un mundo de transformaciones reversibles que afectan el espacio y el tiempo; la vida y la muerte, y prácticamente todas las leyes de la física. Hay materia, pero la materia no es completamente física en el sentido convencional. Es un ámbito siempre anterior al mundo secundario, con tiempos modulares y recombinantes que no se sujetan a la linealidad irreversible del mundo este. En él moran los seres transformadores con capacidad de intervenir en el modo secundario, independientemente de las segmentaciones del espacio y el tiempo en este. Estos seres son antropomórficos; en fin, humanos supervitales, facultados para asumir casi cualquier forma y sustancia. Los animales y otras criaturas nohumanas derivan de estos seres, al igual que los humanos ordinarios actuales. Pero los animales y demás criaturas son no-humanos en el mundo este, dados los cuerpos de diversa naturaleza que les quedaron fijados, aunque en el modo existencial primario todavía puedan asumir su antropomorfismo y sean también humanos. Los actuales humanos, en cambio, quedaron fijados con cuerpo de tales en el mundo este, pero pueden asumir otras corporalidades en el mundo otro. A todo ello se añade la radical opción chamánica de afirmar la continuidad y capacidad de afectación mutua de estos dos modos (o mundos) existenciales y de reconocerle igual o mayor intensidad a uno de ellos, considerando, incluso, que el modo primario (el mundo otro o de la imagen) es, si se puede decir así, el más real. ${ }^{26}$

Volviendo al jaguar, hay que tomar en cuenta antes que nada que este se desdobla en lo que es su fantasma (también "sombra", "carcasa" o "camisa", "cuerpo" en otras traducciones) a partir de lo que es su imagen (en otras traducciones: "espíritu" o "alma", pero también el "dueño", "jefe" o "guardián" que conecta con una pluralidad). En su modo de existencia como imagen o espíritu, el jaguar no solo es persona con todas las de la ley, sino que es antropomórfico; es imagen humana, por lo que, desde su perspectiva propia, se considera a sí mismo humano. Los humanos que permanecen en el modo secundario (o mundo este) verán al jaguar solamente como fantasma, carcasa, en fin, como un animal reducido a su figura zoomórfica. Pero los chamanes y otros humanos que tienen acceso al modo primario (o mundo otro) pueden ver al jaguar en su aspecto antropomórfico primario, es decir: como gente, como humano. Así, el jaguar, desde su perspectiva en cuanto imagen, piensa, habla, vive en familia, tiene casa o maloca, cultiva, canta y baila como cualquier humano. Esta es la manera de ser de muchos animales y, virtualmente, de casi todos los seres. Pero a su vez, el jaguar, e igual otros seres, ven a los humanos que permanecen en el mundo este (secundario), como animales; solo los pueden ver como

26 Sintetizo en estas líneas las aportaciones de Wright y Kopenawa/Albert en las obras citadas. 
gente humana cuando (estos humanos) acceden al modo primario (mundo otro). Es un fenómeno al cual Viveiros le ha llamado perspectivismo. Tal perspectivismo redunda también en un multinaturalismo, porque conlleva la premisa de que todos los seres, bióticos y no bióticos, animales o plantas, comparten, en la modalidad existencial que es el mundo otro (o primario) la facultad de ser persona, sujeto o alma humana, pero los diferencian radicalmente sus distintos cuerpos o naturalezas en el mundo este o secundario. ${ }^{27}$

Vemos, entonces, cómo el esquema de la bestia y el soberano, según es cuestionado por Derrida, se revoluciona cuando lo contraponemos al jaguar y el chamán. El jaguar no acompaña al chamán porque comparta incidentalmente con él una exterioridad natural exterior a la ley, la cultura y la polis. En primer lugar el jaguar acompaña o hace pareja con el chamán porque, independientemente de que sea su amigo o enemigo en determinada coyuntura, es su colega humano, su igual en la isonomía, su posible auxiliar o adversario en el manejo soberano del territorio. El jaguar también es chamán, y más que eso, es maestro de chamanes. En segundo lugar, no hay exterioridad natural porque no hay naturaleza; no existe la naturaleza como algo categorialmente aparte y opuesto al poblamiento humano del territorio. Tanto el jaguar como el chamán son actores del territorio, es decir, de una dimensión cósmica de la pluralidad de seres que abarca a humanos y no humanos, en donde en verdad todos los seres son humanos no empece los cuerpos diferentes que poseen en el modo secundario de existencia. Todo esto es así, por supuesto, desde la perspectiva chamánica del modo existencial primario (o mundo otro) en el cual el chamán se relaciona con el jaguar imagen, persona, más allá del jaguar fantasma limitado al cuerpo zoomórfico. Se trata, recordemos, de una perspectiva otra, que piensa un mundo otro. Hay que enfatizar que ese mundo otro, ese modo primario de existencia, es territorio. El territorio, en la concepción amazónica, es una entidad portentosamente múltiple y diseminada, no se compone de áreas espaciales, sino de instancias activas: sujetos en redes de colaboración y conflicto, en relaciones conjuntivas y disyuntivas, que determinan lo que es el espacio y el lugar, así como el tiempo. En el territorio no hay ontoteología porque todos los seres son personas y por tanto las personas son el mundo; no es que haya personas en un mundo: el mundo es las personas y está en las personas. ${ }^{28}$ Por eso es que, como cuenta Mandu da Silva, los chamanes-jaguar que mueren en el mundo este se van a vivir a las aldeas de los chamanes-jaguar del mundo otro, que son socie-

\footnotetext{
27 Ver Viveiros y pássim.

28 Véase el libro de Déborah Danowski y Eduardo Viveiros de Castro, Há mundo por vir? Ensaio sobre os medos e os fins, páginas 85 y ss.
} 
dades igualitarias sin dios ni rey ni ley. Según resume Robin Wright, "en el mundo otro, las aldeas de chamanes-jaguar son ejemplo de ideal igualitario al que se debe aspirar en el mundo éste" (173). De hecho, no traduzco las expresiones de Wright en inglés "the Other World" y "This World" como el "otro mundo" y "este mundo" para no connotar el corte tajante, unilineal, teleológico e irreversible que impone la ontoteología evangélica y abrahámica, al decir de Derrida, en esa dualidad. En el pensamiento amazónico el mundo otro no niega el mundo este, sino que lo potencia, lo sostiene. Precisamente por ser un modo existencial primario, el mundo otro se orienta hacia el mundo este; es su principio, su tiempo anterior incesante en donde todo es comienzo; no es de ninguna manera el fin ni el cumplimiento de los tiempos, como el "otro mundo" evangélico-abrahámico. No es que el territorio en general sea un espacio de eudemonía ontológica, en que todo propenda "naturalmente' a la armonía, la democracia y la igualdad, sino que los ideales chamánicos se recortan sobre una isonomía constitutiva librada de ontoteologías inmanentes o trascendentes. El territorio es tan pródigo como terrorífico. El territorio no es destino, y si es origen, es un origen que radica en la capacidad de siempre ser otro origen. He ahí su élan político.

Ya hemos dado cuenta del jaguar, comparándolo con la bestia del soberano. Ahora hay que dar cuenta del chamán, y compararlo con el soberano indivisible impugnado por Derrida, tomando en cuenta que ya vimos cómo el jaguar y el chamán son ambos soberanos, colegas en la amistad o en la enemistad, en la alianza o en el conflicto. El chamán es el encargado de fomentar los vínculos; de estimular y agenciar las afectaciones entre el mundo este y el mundo otro. Para conectarse con el mundo otro y trasladarse a él, ir y venir, el chamán tiene que convertirse en un transformador; debe aprender a transformarse en jaguar y en muchos otros animales y seres de pensamiento. El transformador maneja tanto el antropomorfismo como el zoomorfismo, pero lo hace desde el plano de la imagen; desde la perspectiva del mundo otro, que es la que le brinda poderes extraordinarios. Por tanto, el chamán, en sus gestiones y negociaciones, conflictos y alianzas con distintos seres de su entorno, puede asumir formas corporales animales, más o menos zoomórficas, aun polimórficas, pero sin abandonar la perspectiva de la imagen, del espíritu, el cual, recordemos, no deja de ser corpóreo y material de una manera extremadamente plástica que excede la física convencional. El chamán deviene espíritu de jaguar, imagen de jaguar, independientemente de si de hecho asume o no una apariencia mimética, zoomórfica como tal. Robin Wright aclara que los chamanes-jaguar baniwa, como Mandu da Silva, son jaguares en un sentido existencial, espiritual y afectivo, por sus poderes extraordinarios, pero no es que mimeticen el cuerpo fenoménico, zoomórfico del jaguar ni sus cualidades 
ordinarias en el mundo este. ${ }^{29}$ Las capacidades transformadoras, metamórficas, deben considerarse siempre desde el perspectivismo de la doble modalidad de la experiencia. En esa medida, las transformaciones constituyen el interfaz operativo que existe entre los modos fundamentales de experiencia y, en la misma medida, la cosmopolítica se practica, tanto en el mundo este, en el modo existencial secundario, como en el mundo otro, con su modo existencial primario. Son las transformaciones las que potencian la soberanía del jaguar y el chamán, y de muchos otros personajes chamánicos como la boa, el perezoso, el águila, el gavilán tijereta, el guacamayo, la luna, el sol, el trueno, la lluvia, el río, y tantos más, al permitirles actuar entre el mundo primario y el mundo secundario, obteniendo sus poderes extraordinarios en el primero. Estas transformaciones y poderes brindan ese "yo puedo" ilimitado que bien dice Derrida, es decir, esa soberanía en que se potencia la libertad. Ahora bien, hay que ver si la soberanía del chamán, y por extensión de los demás seres que la comparten, es indivisible cual la soberanía articulada sobre la ontoteología de raigambre evangélica y abrahámica en la que permanece gran parte de la filosofía, como dice Derrida.

En el seno de la dinámica amazónica ese "yo puedo" ilimitado, que necesariamente vincula la libertad a la soberanía, al que justamente se refiere Derrida, se transforma en multiplicidad; no tanto en un "nosotros podemos", que sigue siendo un plural del yo, como sí en un "ustedes, ellos y ellas pueden", que son las personas gramaticales realmente inclusivas del otro múltiple. Hay poder, hay soberanía, pero no hay univocidad monolítica; no predomina la ipseidad; la soberanía más bien se divide, se distribuye, se disemina. Así, el chamán es un soberano dividido, como deja ver Wright cuando describe a Mandu da Silva: "El payé es alguien que está constantemente en proceso de 'devenir otro', por lo que apenas se puede hablar de su 'ser' en términos de formas fijas. Tiene más sentido hablar del chamán como una 'multiplicidad de intencionalidades' .. . que, como los espíritus y deidades, se transforma constantemente"... Y cuando cita a Carlos Fausto: "El chamán es un ser múltiple, una micro-población de agencias chamánicas cobijadas en un cuerpo; de ahí que 'sus' intenciones nunca son suyas exclusivamente ni puede él jamás estar seguro de cuáles son sus propias intenciones" (Wright 74). Todo payé, según refleja

29 Uno de los problemas del libro de G. Reichel-Dolmatoff sobre el chamán y el jaguar es que no distingue nítidamente que el chamán se puede transformar en espíritu de jaguar (que bien puede o no manifestar tropismos zoomórficos, ser o no invisible o incluso mantener la figura humana), pero no necesariamente se convierte en un jaguar ordinario (con cuerpo zoomórfico de jaguar). Confróntese con el texto de G. Reichel-Dolmatoff, no listado en la bibliografía: The Shaman and the faguar (Philadelphia: Temple University Press, 1975). 
la biografía de Mandu da Silva, actúa en red, movilizando, reclutando, negociando con aliados humanos del cosmos, que incluyen espíritus dueños de animales, de plantas, de cuerpos de agua, de meteoros climáticos, así como deidades o según prefiero llamarles, seres supervitales muy poderosos instalados en el mundo otro. Un ejemplo de lo que es la actuación en red del chamán lo provee el relato del chamán yanomami Davi Kopenawa sobre una curación, en el que se demuestra que la cura de un enfermo es un asunto cosmopolítico; es la continuación de la política y de la guerra por otros medios, es decir en el otro modo de experiencia. Cuenta Kopenawa que ante los ataques de los ne wari (espíritus de la enfermedad), los espíritus ayudantes del chamán suelen convocar cuadrillas entre sus aliados y auxiliares, dependiendo del caso y las exigencias tácticas. Organizan expediciones de rastreo y cura en busca de los escondites en donde se halla secuestrada la imagen del enfermo. Los perros de caza, los pecaríes y sobre todo el rapaz koimari (entiéndase sus imágenes) brindan particular ayuda, pero los xapiri ${ }^{30}$ más hábiles son los propios yernos de los ne wari, pues estos se les pueden aproximar sin levantar sospechas: "Ellos dirigen las expediciones de rastreo y cura. Tan pronto como divisan a los seres malignos, pretenden entablar con ellos un diálogo de invitación hiimu para disipar cualquier desconfianza. Y de pronto les caen a machetazos, a lo que se suman sus acompañantes" (Kopenawa 212-213). Algo parecido, cuenta Kopenawa, ocurre cuando es cuestión de perseguir, por ejemplo, a Omoari, el ser maligno de la sequía. Entonces dirigen la expedición los diversos yernos del propio Omoari, más los espíritus de la cigarra, la mariposa, el lagartijo, las abejas remoremo moxi, los pájaros hatakuna mo, kookata mo, okreahama, y el lagarto gigante wasikara. Pero como resulta que el rastro de Omoari es caliente como la brasa, deben acudir también en su ayuda los sapos yoyo, hwatupa y prooma koko, y derramar sin pausa totumas de agua sobre la senda para evitar que los xapiri lanzados en la búsqueda se quemen los pies. Igual contribuyen a asperjarlos con agua los espíritus porari de las cascadas y los de las nutrias proro y kana. El poderoso espectro de Porepatari cubre a los atacantes con sus flechas untadas de curare. Tan pronto los yernos se aproximan al enemigo, fingiendo que van a dialogar para hacerle una invitación a una fiesta reahu, todos le caen encima sin miramientos. Este tipo de acción en red se basa en alianzas y afinidades políticamente construidas, con paciencia y dedicación, entre todos los participantes. Cabe insistir en que la agencia es siempre concertada

30 Los xapiri son los multitudinarios seres chamánicos, maestros y auxiliares de los chamanes yanomami; existen en el plano de la imagen y generalmente asumen la forma de hombres y mujeres diminutos de extraordinaria belleza con atuendos de guerreros danzantes. Todo chamán yanomami vive enamorado de sus xapiri. 
y nunca surge de una voluntad e iniciativa única o unilateral. Otro ejemplo es el caso de los baniwa con personajes supervitales como Kuwai (Yuruparí) y Dzuliferi, quienes asumen los roles de maestros y tutores de sus protegidos animales y humanos, y les transmiten conocimientos y poderes, pero a su vez son influidos y afectados por sus protegidos mediante acciones taumatúrgicas.

Para resumir: la práctica del chamán es un ejemplo de lo que Fernando Savater llama el "simpoder", ya que el poder y el conocimiento que pasan por su persona se distribuyen entre seres que no son ob-jeto del conocimiento, sino siempre sujetos activos, perspectivas de conocimiento. Como comenta Viveiros, cuando un chamán quiere conocer a otro ente, se le aproxima para saber qué piensa, qué desea, cómo lo ve a él y qué es capaz de hacer. Este conocimiento es práctica de una multitud de personas con cuerpos antropomórficos y zoomórficos, bióticos y abióticos en el modo existencial secundario, pero con imágenes humanas en el modo existencial primario, en donde ninguna de ellas yace como objeto sometido a un acto de conocimiento unifocal o unilateral captador de la totalidad. Desde esa mira ampliada, cosmopolítica, que es mirar cómo mira el otro, la verdad no es totalidad objetiva, sino relación entre perspectivas subjetivas. Esta distribución reversible, multifocal, del deseo y de la agencia entre la multitud, es congruente con la práctica en las relaciones sociales y políticas de un chamán-jaguar como Mandu da Silva, quien cuando le tocó ser líder de su comunidad se dedicó a mediar, a negociar, a conciliar en los conflictos y a exhortar; a apoyar gestiones colectivas de bienestar común, sin dar órdenes ni acumular poder, bienes, ni otra influencia que no proviniera de su experiencia y autoridad moral e intelectual. De la misma forma, Davi Kopenawa ha actuado como un mediador, un conciliador y un consultor de los yanomami con base en su experiencia, y autoridad moral e intelectual, sin ampararse en ninguna posición de poder vertical. En su caso, es impresionante el hecho de que haya logrado internacionalizar y globalizar un mensaje chamánico de su comunidad, que aboga por la defensa de las tierras yanomami de la violencia y la depredación de mineros y rancheros, y del Amazonas como santuario ecológico, sin acumular ventajas políticas ni económicas; regresando siempre, como cualquier hijo de vecino, a su comunidad a talar la chagra; a cazar para poder comer, y a luego dormir en la hamaca que le corresponde en la casa comunal. Con relación a este punto cabe señalar que la dinámica política interna de las comunidades amazónicas indígenas autónomas sigue siendo similar, a grandes rasgos, a la analizada hace medio siglo por Pierre Clastres en su obra La sociedad contra el Estado. Predomina todavía un ethos igualitario, y funcionan mecanismos micro-políticos diversos que atajan y contravienen cualquier señal de acumulación de poder y riquezas 
en los líderes comunales, ya sea el jefe o el chamán. ${ }^{31}$ Como se sabe, al chamán le corresponde más que nada la cosmopolítica, y al jefe de maloca o autoridad comunal le toca la política local; pero una persona puede asumir ambas funciones. El chamán, llámese taita, payé, tradicional, o piache, es un personaje que no acumula poder ni pretende dirigir congregaciones de fieles; y que tampoco predica ni exige fidelidad a ningún credo. Mucho menos promueve el culto masivo ni practica la posesión ni el sacrificio rituales. ${ }^{32} \mathrm{El}$ chamán tiene que procurar su comida y la de su familia como cualquier otro miembro de la comunidad. Las infaltables excepciones a esta regla son escasas y atípicas. Las tradiciones de la sociedad contra el Estado perviven dentro del limitado ámbito que todavía resta y que se mantiene ante la influencia del Estado propio de cada jurisdicción nacional de la región amazónica. No obstante, sin afanes puristas y más allá de constatar la pervivencia de las prácticas tradicionales, lo que interesa enfatizar aquí es que el pensamiento comunicado por estas tradiciones constituye una aportación clave a la crítica de la soberanía indivisible consustancial al Estado moderno-industrial, e inspira al pensamiento contemporáneo a imaginar una posible cosmopolítica global capaz de responder a la mutación biopolítica contemporánea que, al decir de Jacques Derrida, hace tambalear o pone a "temblar los límites del paso de las fronteras entre bios y zoe, zoológico y antropológico, igual que entre vida y muerte, vida y técnica, vida e historia, etc." (El animal que luego estoy si(gui)endo 40). Según hemos comenzado a ver, si algo hace el pensamiento amazónico es complicar, espesar, desalinear, plegar, dividir (como hemos dicho arriba, parafraseando a Derrida) y multiplicar las fronteras entre todas esas categorías, practicando transformaciones y conexiones en el

31 Se debe aclarar, sin embargo, que el igualitarismo amazónico no siempre excluye ciertas expresiones de jerarquía (o heterarquía) relacionadas con la edad, los conocimientos tradicionales, el género, y los linajes ancestrales. Ver el libro de Jon Shackt, A People of Stories in the Forest of Myth. The Yukuna of Miritiparaná (95); y el de Irving Goldman (55). Este último es uno de los autores que más insiste en la importancia de la jerarquía en ciertas sociedades amazónicas, pero no deja de constatar que en estas jerarquías: 1) el estatus personal es secundario, predominando su relación con procesos míticos y místicos (89), haciéndole contrapeso un fuerte ethos igualitario (101); 2) se invierte el principio de las sociedades de estado en las cuales los fuertes aglutinan a los débiles, siendo aquí los débiles quienes aglutinan a los fuertes (74); y 3) que los "dueños" o "jefes" no son soberanos en el sentido "civilizado" de ejercer poder unilateral sobre otros (98-99).

32 Véanse los textos de Eduardo Viveiros de Castro, La mirada del jaguar (64) y "Chamanismo y sacrificio: un comentario amazónico", contenido en el texto editado por Jean-Pierre Chaumeil, Roberto Pineda Camacho y Jean-François Bouchard, Chamanismo y sacrificio. Perspectivas arqueológicas y etnológicas en sociedades indígenas de América del Sur (335-347). 
marco de una concepción del territorio del poblamiento humano entendido como multiplicidad de seres y actores con naturalezas y perspectivas inconmensurables.

\section{Obras citadas}

Århem, Kaj, Luis Cayón, Gladys Angulo y Maximiliano García, comps. Etnografía Makuna. Tradiciones y saberes de la Gente de Agua.

Götheborg - Bogotá: Acta Universitatis Gothoburgensis - Instituto

Colombiano de Antropología e Historia, 2004. Impreso.

Brassier, Ray. Nihil Unbound. Enlightment and Extinction.

New York: Palgrave Macmillan, 2013. Impreso.

Chakravarty, Dipesh. "Clima e historia: cuatro tesis". Trad. Anaclet

Pons. Revista Pasajes 31 (2010): 51-68. Impreso.

Clastres, Pierre. Society Against the State. Essays on Political Anthropology. New York: Zone Books, 1987. Impreso.

Danowski, Déborah y Eduardo Viveiros de Castro. Há mundo por vir? Ensaio sobre os medos e os fins. Florianópolis: Cultura e Barbarie - Instituto Socioambiental, 2014. Impreso.

Deleuze, Gilles. Abecedario de Gilles Deleuze (1988) - De la "A" a la "Z". Rosario:

Centro de Estudios e Investigación de Medicina y Arte, 2001. Impreso.

Deleuze, Gilles y Félix Guattari. Mil mesetas. Capitalismo y esquizofrenia II. Trad. José Vázquez Péres y Umbelina Larraceta. Valencia: Pre-Textos, 2004. Impreso. Derrida, Jacques. De la gramatología. Trad. Óscar del Barco.

Buenos Aires: Siglo XXI, 1971. Impreso.

Derrida, Jacques. El animal que luego estoy si(gui)endo. Trad. Cristina de Peretti y Cristina Rodríguez Marciel. Madrid: Trotta, 2008. Impreso.

Derrida, Jacques. The Beast and the Sovereign Vols. I-II. Trad. Geoffrey

Bennington. Chicago: University of Chicago Press, 2009-2011. Impreso.

Derrida, Jacques. Posiciones. Trad. Manuel Arranz. Valencia: Pre-textos, 2014. Impreso.

Descola, Philippe. Beyond Nature and Gulture. Trad. Janet Lloyd.

Chicago: University of Chicago Press, 2013. Impreso.

Garcia, Tristan. Forme et objet. Un traité des choses. Paris:

Presses Universitaires de France, 2010. Impreso.

Goldman, Irving. Cubeo Hehénewa Religious Thought. Metaphysics of a Northwestern Amazonian People. New York: Columbia University Press, 2004. Impreso.

Hillix, W.A. y Duane Rumbaugh. Animal Bodies, Human Minds. Ape, Dolphin, and Parrot Language Skills. New York: Kluwer Academic/Plenum Publishers, 2004. Impreso. 
Kopenawa, Davi y Bruce Albert. La Chute du ciel. Paroles d'un chaman yanomai. Paris: Plon, 2010. Impreso.

Lévi Strauss, Claude. Tristes trópicos. Trad. Noelia Bastard. Buenos Aires: Paidós, 1988. Impreso.

Mancuso, Stefano y Alesandra Viola. Brilliant Green. The Surprising History and Science of Plant Intelligence. Washington: Island Press, 2015. Impreso.

Massumi, Brian. What Animals Teach Us about Politics. Durham - London: Duke University Press, 2014. Impreso.

Mazzoldi, Bruno. Negro de Yurupary - Púrpura de Prince. Apuntes para una cromometría de la violencia melancólica. San Juan de Pasto, Colombia: Impresión mimeográfica, s.f. Impreso.

Mazzoldi, Bruno. "Derrida desde las Indias". A veces Derrida. Bogotá: Universidad Externado, 2013. 15. Impreso.

Raffles, Hugh. Insectopedia. New York: Pantheon Books, 2010. Impreso.

Reichel-Dolmatoff, Gerardo. The Shaman and the faguar. Philadelphia: Temple University Press, 1975. Impreso.

Scahill, Jeremy. "The Assassination Complex". The Intercept. Web. 15 de octubre de 2015.

Shackt, Ver Jon. A People of Stories in the Forest of Myth. The Yukuna of Miritiparaná. Oslo: Instituttet for sammenlignende kulturforskning, 2013. Impreso.

Viveiros de Castro, Eduardo. "Chamanismo y sacrificio: un comentario amazónico". Chamanimo y sacrificio. Perspectivas arqueológicas y etnológicas en sociedades indígenas de América del Sur. Eds. JeanPierre Chaumeil, Roberto Pineda Camacho y Jean-François Bouchard. Bogotá: Instituto Francés de Estudios Andinos, 2003. Impreso.

Viveiros de Castro, Eduardo. Metafísicas caníbales. Líneas de antropología postestructural. Trad. Stella Mastrangelo. Buenos Aires: Katz, 2010. Impreso.

Viveiros de Castro, Eduardo. La mirada del jaguar. Buenos Aires: Tinta Limón, 2013. Impreso.

Wolfe, Cary. Before the Law. Humans and Other Animals in a Biopolitical Frame. Chicago: University of Chicago Press, 2013. Impreso.

Wright, Robin. Mysteries of the Faguar Shamans of the Northwest Amazon. Lincoln - London: University of Nebraska Press, 2013. Impreso. 